\title{
Avaliação da genotoxicidade da llex paraguariensis (erva mate) pelo teste do micronúcleo
}

\author{
ALBAS, C.S.'; SOUZA, J.P.'; NAI, G.A."; PARIZI, J.L.S'. \\ 'Universidade do Oeste Paulista (UNOESTE), Rua José Bongiovani, 700, CEP 19050-680, Presidente Prudente, \\ SP, Brasil, *autor responsável pela correspondência: patologia@unoeste.br
}

RESUMO: A llex paraguariensis é espécie nativa da América do Sul. O consumo de erva mate tem sido associado ao aumento nas taxas de câncer oral, de orofaringe, esôfago e laringe. $\mathrm{O}$ objetivo deste estudo foi investigar o potencial genotóxico da exposição a dose única de llex paraguariensis através do teste do micronúcleo. Para este estudo, foram utilizados 32 ratos Wistar albinos machos e adultos, divididos em 4 grupos: A - Composto por 8 ratos que receberam infusão de chá preparado na concentração de $5 \%$ de erva mate (concentração usualmente encontrada no chá de consumo humano); B - Composto por 8 ratos que receberam chá preparado por imersão em água fria na concentração de $5 \%$ de erva mate; C - Composto por 8 ratos, os quais receberam ciclofosfamida em dose única subcutânea $(50 \mathrm{mg} / \mathrm{kg})$ no primeiro dia do experimento (grupo controle positivo); D - Composto por 8 ratos, os quais receberam somente água (grupo controle negativo). Todos os animais receberam ração ad libitum. Os animais dos grupos $\mathrm{A}, \mathrm{B}$ e $\mathrm{D}$ foram submetidos à eutanásia 48 horas após o início do experimento e os do grupo C, 24 horas após. Foi coletado material da medula óssea de cada rato após a eutanásia para realização do teste do micronúcleo em eritrócito policromático, para avaliação do grau de genotoxicidade. A mediana de micronúcleos para o grupo $\mathrm{A}$ (chá mate preparado com infusão) foi de 0,00 , do grupo $B$ (chá mate em imersão em água fria) foi de 0,00 , do grupo C (ciclofosfamida - controle positivo) foi de 9,00, e no grupo $D$ (controle negativo) foi de 0,00. Não se observou genotoxicidade da llex paraguariensis, em ambas as formas de preparo do chá, através do teste de micronúcleo, ao nível de significância de $5 \%$.

Palavras-chave: infusão, erva-mate, eritrócito policromático, genotoxicidade, teste do micronúcleo.

ABSTRACT: Evaluation of the genotoxicity of llex paraguariensis (yerba mate) by micronucleus test. The Ilex paraguariensis is a native species of South America. Yerba mate consumption has been associated with increased rates of oral, oropharynx, esophagus and larynx cancer. The aim of this study was to investigate the genotoxic potential of the exposure to a single dose of Ilex paraguariensis by the micronucleus test. For this study, 32 male, adult Wistar rats were used, divided into 4 groups: A - Consisting of 8 rats, which received an infusion of tea prepared at a concentration of $5 \%$ of mate (concentration usually found in human consumption of tea); B - Consisting of 8 rats, which received tea prepared immersed in cold water at a concentration of $5 \%$ of mate; $C$ - Consisting of 8 rats, which received a single subcutaneous dose of cyclophosphamide $(50 \mathrm{mg} / \mathrm{kg}$ ) on the first day of the experiment (positive control group); D - Consisting of 8 rats, which received only water (negative control group). All animals received food ad libitum. The animals in groups A, B and D were sacrificed 48 hours after the beginning of the experiment and group C, 24 hours after. Material from the bone marrow of each rat was collected after euthanasia to perform the micronucleus test in polychromatic erythrocyte to assess the degree of genotoxicity. The median of micronuclei for group A (mate tea prepared with infusion) was 0.00 , for group B (mate tea immersed in cold water) was 0.00 , for group C (cyclophosphamide - positive control) was 9.00 and for group D (negative control) was 0.00 . No genotoxicity of Ilex paraguariensis was observed in both tea preparation methods by the micronucleus test at a significance level of $5 \%$.

Keywords: yerba mate infusion, polychromatic erythrocyte, genotoxicity, micronucleus test.

Recebido para publicação em 06/06/2012 


\section{INTRODUÇÃO}

A llex paraguariensis (erva mate) é uma espécie nativa da América do Sul que pertence à família Aquifoliaceae (Goldenberg et al., 2003). Suas folhas são utilizadas para fazer bebidas como chimarrão, tererê, mate solúvel, chá mate, além de preparações farmacêuticas (Gosmann, 1989). O seu maior consumo ocorre nas regiões Sul e Sudeste do Brasil, local de maior produção, em torno de 650.000 toneladas de folhas ao ano (Esmelindro et al., 2002).

O tererê, uma bebida feita com a imersão de erva mate (Ilex paraguariensis), consumida geralmente com água gelada, também é muito consumida em infusão (Nakamura, 2008).

O estudo da constituição química das folhas de Ilex paraguariensis demonstrou a presença de alcalóides, polifenóis, flavonóides, triterpenos e ácidos orgânicos (Valduga et al., 1997), além de altos teores de cafeína, teobromina, e taninos, (Borille et al., 2005). As metilxantinas cafeína, teobromina e teofilina são os compostos mais conhecidos desta espécie, responsáveis pela ação estimulante atribuída à erva mate (Nakamura, 2008).

A International Agency for Research on Cancer (IARC) avaliou o risco carcinogênico do mate e concluiu que há evidências limitadas de carcinogenicidade para o mate quente e que não há dados disponíveis sobre beber mate frio ou sobre sua carcinogenicidade em modelos experimentais com animais (IARC, 1991). Ambos os mecanismos carcinogênicos, químico e térmico, têm sido sugeridos para erva mate (Goldenberg et al., 2003).

$O$ câncer mais frequentemente mencionado em associação com mate quente ingerido com bombilla foi o do esôfago (Loria et al., 2009). A interação entre mate, álcool e tabaco, além de outros fatores, pode desempenhar um papel determinante no processo carcinogênico. O uso de tabaco e álcool conjuntamente ao de mate quente são dois fatores de confusão na análise dos casos de câncer de esôfago (Goldenberg et al., 2003; Loria et al., 2009).

Diferentes concentrações de hidrocarbonetos aromáticos policíclicos (HAP) são encontradas na erva mate nos diferentes produtos comerciais e nas preparações a quente e a frio (Zuin et al., 2005; Kamangar et al., 2008). Isto sustenta a hipótese que o risco de câncer associado com ingestão de mate pode não estar relacionado somente à temperatura, mas também ao nível de compostos carcinogênicos presentes (Loria et al., 2009). Diferenças nos processos de preparo da erva mate podem produzir diferentes níveis de HAP no produto final (Loria et al., 2009).

Em contrapartida, alguns estudos mostram que a erva mate é rica em compostos fenólicos, o que poderia inibir a proliferação do câncer oral, via inibição da topoisomerase II (Mejía et al., 2005), mostrando que o tema é controverso.

O teste de micronúcleo é uma das ferramentas amplamente utilizadas para a pesquisa e aferição da segurança de inúmeras substâncias, classificando-as ou não como genotóxicas/ mutagênicas e fornecendo resultados com forte suporte estatístico (Fenech et al., 1999).

A Ilex paraguariensis (erva mate) é largamente consumida, principalmente nas regiões Sul e Sudeste do Brasil; deste modo, avaliar seu possível potencial genotóxico é importante para delimitação de seu uso, principalmente por não haver muitas publicações com uso do chá mate preparado com água fria. Assim, o objetivo desta pesquisa foi investigar a genotoxicidade da exposição à dose única de llex paraguariensis preparada com água quente e com água fria, pelo teste do micronúcleo.

\section{MATERIAL E MÉTODO}

\section{Procedimento experimental}

Para este estudo, foram utilizados 32 ratos Wistar albinos, machos e adultos, com peso entre 200 a $250 \mathrm{~g}$. Os ratos foram separados em número de quatro em caixas retangulares, medindo $49 \times 34 \times 16 \mathrm{~cm}$, as quais foram colocadas em biotério climatizado em umidade (70\%) e temperatura (20$21^{\circ} \mathrm{C}$ ) e equipado com ciclo de 12 horas de claro e escuro.

Os animais foram divididos em quatro grupos: A - Composto por 8 ratos que receberam infusão de chá numa concentração de $5 \%$ de erva mate para chimarrão (Erva mate Laranjeiras, Indústria Mate Laranjeiras LTDA, Laranjeiras do Sul, Paraná, Brasil); B - Composto por 8 ratos que receberam chá preparado com água fria numa concentração de $5 \%$ de erva mate para chimarrão; C - Composto por 8 ratos, os quais receberam ciclofosfamida (Genuxal, Baxter Oncology $\mathrm{GmbH}$, Halle/Westfalen, Alemanha) em dose única subcutânea $(50 \mathrm{mg} / \mathrm{kg})$ no primeiro dia do experimento (grupo controle positivo) (Ribeiro, 2003); D - Composto por 8 ratos, os quais receberam somente água (grupo controle negativo). Todos os animais receberam ração à vontade.

O chá com erva mate foi preparado com água potável de abastecimento na concentração de $5 \%$, baseada na concentração que os chás são normalmente preparados para consumo por seres humanos. A infusão com água quente foi realizada da seguinte forma: a água foi fervida, retirada do fogo e adicionada sobre a erva mate, a qual estava contida em outro vasilhame. O chá feito com água fria foi realizado com imersão da erva-mate em água fria da seguinte forma: a água foi resfriada a $5^{\circ} \mathrm{C} \mathrm{e}$ então foi jogada sobre a erva mate, a qual estava

Rev. Bras. PI. Med., Campinas, v.16, n.2, supl. I, p.345-349, 2014. 
alojada em outro vasilhame. A erva mate ficou em contato com a água quente ou água fria por 15 minutos e, a seguir, o chá assim obtido foi transferido para bebedouros $(300 \mathrm{ml})$.

O chá foi administrado via bebedouro na dose de 7,0 a $8,0 \mathrm{ml} / \mathrm{g}$ de peso, a temperatura ambiente durante 48 horas. O cálculo da dose foi baseado na ingestão diária média de 2 litros de chá de erva mate por um indivíduo adulto de 60 $\mathrm{kg}$ (Sewram et al., 2003). Após a ingestão dessa quantidade de chá, os ratos receberam água ad libitum.

Os animais dos grupos $A, B$ e $D$ foram submetidos à eutanásia 48 horas após o início do experimento e os do grupo C, 24 horas após. A eutanásia foi realizada com pentobarbital sódico (Syntec, EUA), na dose de $100 \mathrm{mg} / \mathrm{kg}$ administrado na cavidade peritoneal. Os indicativos de morte foram: ausência de movimentos respiratórios, ausência de batimentos cardíacos e perda dos reflexos (Paiva et al., 2005).

Foi coletado material da medula óssea do fêmur de cada rato após a eutanásia e foram realizadas duas lâminas por animal. As lâminas foram coradas pelo corante de Giemsa (Dolles, São Paulo, Brasil). Para determinação do número de micronúcleos foram contados 2000 eritrócitos policromáticos por animal (1000 em cada lâmina) utilizando-se microscópio óptico, no aumento de 400x (Ribeiro, 2003). A análise das lâminas foi cega e realizada por um único avaliador (GAN).

\section{Análise estatística}

A variável frequência de micronúcleos apresentou normalidade pelo teste de KolmogorovSmirnov $(p=0,075)$ e o teste de Levene apresentou não homogeneidade das variâncias $(p=0,004)$, portanto, optou-se pelo uso do teste não paramétrico de Kruskal-Wallis, seguido de comparação múltipla dos postos pelo teste de Dunn. Os testes estatísticos foram realizados ao nível de significância de 5\%.

\section{Aprovação pela Comissão de Ética no Uso de Animais \\ Este estudo foi aprovado pela Comissão de Ética no Uso de Animais da Universidade do Oeste Paulista (CEUA/UNOESTE - Protocolo n. 765/11).}

\section{RESULTADOS}

A mediana de micronúcleos para o grupo $A$ (chá mate preparado com infusão) foi de 0,00 , do grupo $B$ (chá mate em imersão em água fria) foi de 0,00 , do grupo $C$ (ciclofosfamida - controle positivo) foi de 9,00 e no grupo $D$ (controle negativo) foi de 0,00 (Figura 1 e Tabela 1 ).

Não houve diferença na frequência de micronúcleos em relação à temperatura da água de preparo (quente ou fria) do chá mate em relação ao grupo controle negativo $(p>0,05)$, somente em relação ao grupo controle positivo $(p=0,00001)$.

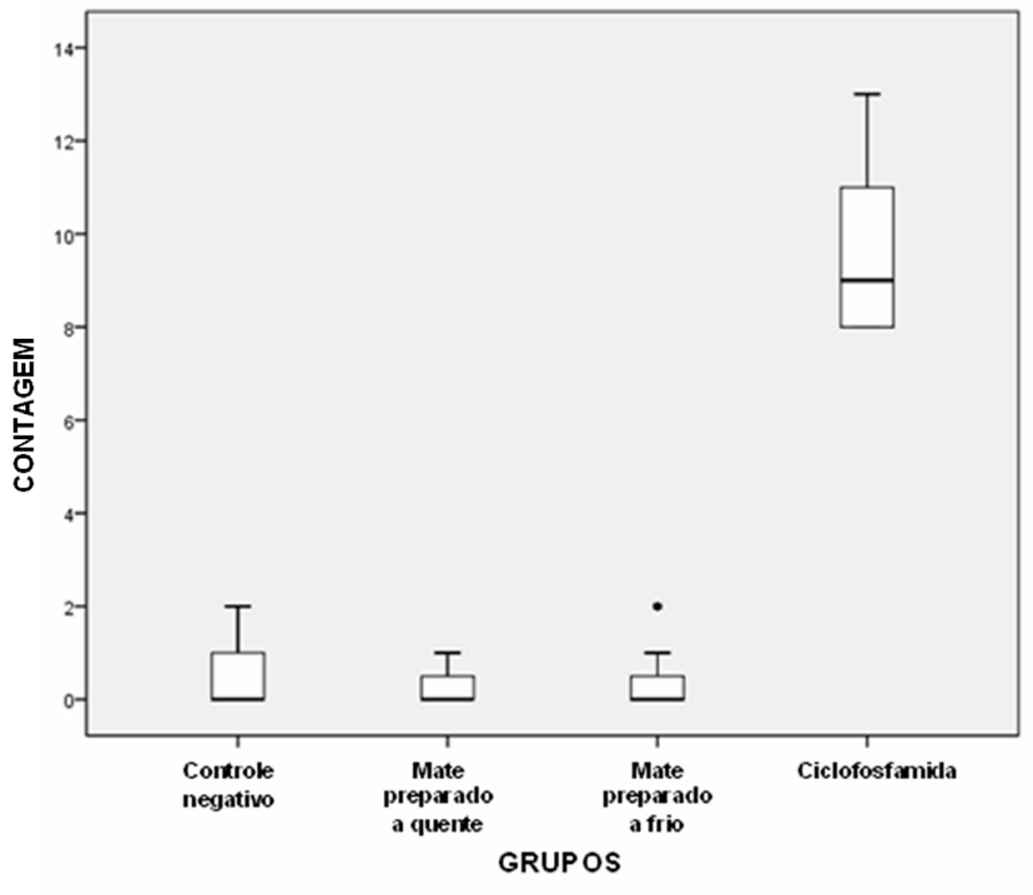

FIGURA 1. Mediana e intervalo interquartílico da contagem de micronúcleos de ratos que receberam ou não (controle negativo) na água de beber mate preparado com água quente ou fria ou ainda $50 \mathrm{mg} / \mathrm{kg}$ de ciclofosfamida, por via subcutânea (controle positivo). $\mathrm{N}=8$ animais por grupo. $\bullet$ : outlier. 
TABELA 1. Mediana e intervalo interquartílico da frequência de micronúcleos em cada grupo estudado.

\begin{tabular}{ccc}
\hline GRUPO & Mediana & \\
& & Intervalo interquartílico \\
\hline Grupo A & $0,00^{\mathrm{a}}$ & 0,25 \\
Grupo B & $0,00^{\mathrm{a}}$ & 0,25 \\
Ciclofosfamida & $9,00^{\mathrm{b}}$ & 3,00 \\
Controle negativo & $0,00^{\mathrm{a}}$ & 1,00 \\
\hline
\end{tabular}

A: chá mate preparado com água quente; $B$ : chá mate preparado com água fria; Ciclofosfamida: controle positivo. Resultados com diferentes sobrescritos diferem significativamente $(p<0,05)$.

\section{DISCUSSÃO}

O mate é consumido de diversas maneiras, mas o método mais popular é através da colocação da erva mate no copo (de metal de prata ou um vaso de cerâmica em forma de jarro), derramar água fervente nela e tomar o líquido infundido através de um canudo de metal chamado bombilla que atua como um filtro que impede as folhas de subirem no canudo. Por outro lado, também pode ser consumida como bebida fria (tererê) de acordo com a preferência individual (Loria et al., 2009).

A IARC classificou 0 ato de beber mate quente como "provável cancerígeno" para humanos (Grupo 2A) e o mate em si como não "classificável quanto a sua carcinogenicidade" para humanos (Grupo 3) (IARC, 1991).

Vários estudos encontraram uma associação entre a temperatura da infusão da erva mate e os riscos de câncer oral, esôfago e/ou laringe (Barros et al., 2000; De Stefani et al., 2002). Assim, a causa do chá mate provocar câncer seria devida à lesão térmica pelo contato direto da mucosa com a bebida quente. Entretanto, isto não explica a ocorrência de cânceres em outros locais que não tem contato direto da mucosa com a bebida quente, como, por exemplo, a associação com o câncer de bexiga (Loria et al., 2009).

O efeito da ingestão do mate foi avaliado num estudo de caso controle em pacientes com câncer de rim no Uruguai e foi observado que havia um risco três vezes maior, ajustado para outros fatores de risco, para aqueles pacientes que relataram ingerir dois litros ou mais de chá mate por dia. Os autores sugeriram que a presença de ácido cafeíco e/ou o efeito diurético do chá pode estar associado com este risco aumentado (De Stefani et al., 1998). Devido a esta possível relação entre a quantidade de chá consumida e desenvolvimento de câncer, os animais neste estudo foram expostos a dose única de uma quantidade de chá mate relativa ao consumo de dois litros de chá ao dia por um ser humano adulto de $60 \mathrm{~kg}$.

Candreva et al. (1993), em estudo utilizando o modelo com Saccharomyces cerevisiae, observou que o tratamento das culturas com infusão de mate a $30^{\circ} \mathrm{C}$ era capaz de induzir efeito mutagênico muito baixo. Os maiores efeitos mutagênicos observados para este modelo foram obtidos com hipertermia, porém este efeito foi dependente do tempo de exposição. A cafeína quente também foi mutagênica para este sistema (Candreva et al., 1993) e usada nas mesmas concentrações do mate manifesta um efeito genotóxico e citotóxico mais potente, o que pode contribuir, pelo menos em parte, para os efeitos provocados pelo extrato de erva mate (Candreva et al., 1993; Wnuk et al., 2009).

O extrato aquoso da llex paraguariensis foi genotóxico para os modelos com Escherichia coli e Salmonella typhimurium, sendo capaz de intervir em vários estágios metabólicos, mostrando sua atividade genotóxica. Além disso, o extrato de mate pode produzir várias alterações cromossômicas em linfócitos humanos (Fonseca et al., 2000). Contudo, os estudos sobre a genotoxicidade do extrato da llex paraguariensis não são homogêneos (Loria et al., 2009), além de não haverem estudos avaliando esta planta em relação ao seu preparo com água fria.

O teste do micronúcleo detecta substâncias genotóxicas que quebram os cromossomos (clastogênicas) ou que interferem na formação do fuso mitótico, alterando a distribuição equitativa dos cromossomos durante a divisão celular (aneugênicas) (Flores \& Yamaguchi, 2008; KirschVolders et al., 2003). O micronúcleo é um corpúsculo cromatínico adicional e separado do núcleo principal de uma célula durante a divisão celular constituído por cromossomos (aneugênese) ou seus fragmentos (clastogênese) que se atrasam em relação aos demais. Resulta de alterações estruturais cromossômicas espontâneas ou experimentais induzidas ou ainda, falhas no fuso celular, sendo, portanto, excluído dos novos núcleos formados por ocasião da telófase (Ramirez \& Saldanha, 1998; Kirsch-Volders et al., 2003). Não observamos na literatura pesquisada, avaliação do potencial genotóxico da llex paraguariensis através deste teste.

No presente estudo, não houve diferença

Rev. Bras. PI. Med., Campinas, v.16, n.2, supl. I, p.345-349, 2014. 
na frequência de micronúcleos nos eritrócitos policromáticos observados em relação à temperatura da água de preparo (quente ou fria) do chá mate. Em ambos os casos, a frequência de micronúcleos não mostrou diferença significativa em relação ao grupo controle negativo.

Conclui-se que não há genotoxicidade da Ilex paraguariensis, em ambas as formas de preparo do chá, pelo do teste do micronúcleo em eritrócitos policromáticos da medula óssea. Porém, este teste é um teste inicial de genotoxicidade. Outros testes que avaliem genotoxicidade e mutagenicidade devem ser aplicados para que se possa descartar de forma definitiva que a erva mate e a sua forma de preparo (a quente ou a frio) não são genotóxicas. Além disso, estudos com exposição crônica a llex paraguariensis também serão importantes para avaliar a genotoxicidade desta planta.

\section{REFERÊNCIA}

BARROS, S.S. et al. Mate (chimarrão) é consumido em alta temperatura por população sob risco para o carcinoma epidermóide de esôfago. Arquivos de Gastroenterologia, São Paulo, v.37, n. 1, p. 25-30, 2000. BORILLE, M.; REISSMANN, C.B.; FREITAS, R.J.S. Relação entre compostos fitoquímicos e o nitrogênio em morfotipos de erva-mate (Ilex paraguariensis St.Hil.). Boletim Centro de Pesquisa de Processamento de Alimentos, Curitiba, v.23, n.1, p.183-198, 2005.

CANDREVA, E.C. et al. Mutagenicity induced by hyperthermia, hot mate infusion, and hot caffeine in Saccharomyces cerevisiae. Cancer Research, Chicago, v.53, n.23, p.5750-5753,1993.

DE STEFANI, E. et al. Meat intake, 'mate' drinking and renal cell cancer in Uruguay: a case-control study. British Journal of Cancer, London, v.78, p.1239-1243, 1998.

DE STEFANI, E. et al. Food groups and risk of squamous cell carcinoma of the esophagus: a case-control study in Uruguay. British Journal of Cancer, London, v.89, n.7, p.1209-1214, 2002.

ESMELINDRO, M.C. et al. Caracterização físico-química da erva-mate:Influência das etapas do processamento industrial. Ciência e Tecnologia Alimentar, Campinas, v.22, n.2, p.193-204, 2002.

FENECH, M. et al. The HUman MicroNucleus Project An international collaborative study on the use of the micronucleus technique for measuring DNA damage in humans. Mutation Research, Amsterdan, v.428, n.1-2, p.271-283, 1999.

FLORES, M.; YAMAGUCHI, U.M. Teste de Micronúcleo: uma triagem para avaliação genotóxica. Saúde e Pesquisa, Maringá, v. 1, n. 3, p. 337-40, 2008.

FONSECA, C.A. et al. Nontoxic, mutagenic, and clastogenic activities of Mate-Cimarrao (Ilex Paraguariensis). Journal of Environmental Pathology, Toxicology and Oncology, New York, v.19, n.4, p.333-46, 2000.

GOLDENBERG, D.; GOLZ, A.; JOACHIMS, H.Z. The bevereage mate: a risk factor for cancer of the head and neck. Head \& Neck, New York, v.25, n.7, p.595-601, 2003. doi: 10.1002/hed.10288.

GOSMANN, G. Saponinas de Ilex paraguariensis St. Hil. (erva mate). 1989. 108 p. Dissertação (Mestrado em Farmácia), Universidade Federal do Rio Grande do Sul, Porto Alegre, 1989.

INTERNATIONAL AGENCY FOR RESEARCH ON CANCER. Coffee, tea, methylxantines and methylglyoxal. In: IARC Monographs on the evaluation of carcinogenic risks of chemicals to humans. Lyon:IARC, 1991. (Scientific Publication 51).

KAMANGAR, F. et al. High levels of carcinogenic polycyclic aromatic hydrocarbons in mate drinks. Cancer Epidemiology, Biomarkers \& Prevention, Philadelphia, v.17,n. 5, p.1262-1268, 2008.

KIRSCH-VOLDERS, M. et al. Report from the in vitro micronucleus assay working group. Mutation Research, Amsterdan, v.540, n.2, p.153-63, 2003.

LORIA, D.; BARRIOS, E.; ZANETTI, R. Cancer and yerba mate consumption: a review of possible associations. Revista Panamericana de Salud Publica, Washington, v.25, n.6, p.530-539, 2009.

MEJÍA, E.G. et al. Effect of yerba mate (Ilex paraguariensis) tea on topoisomerase inhibition and oral carcinoma cell proliferation. Journal of Agricultural and Food Chemistry, Washington, v.53, n.6, p.1966-1973, 2005. doi: 10.1021/jf048158g.

NAKAMURA, K.L. Variabilidade genética e métodos de extração de metilxantinas e compostos fenólicos em erva-mate (Ilex paraguariensis). 2008. 80 f. Dissertação (Mestrado em Biotecnologia aplicada à agricultura) Universidade Paranaense, Umuarama, 2008.

PAIVA, F.P.; MAFILLI, V.V.; SANTOS, A.C.S. Curso de Manipulação de Animais de Laboratório. Rio de Janeiro: Fundação Osvaldo Cruz, Centro de Pesquisas Gonçalo Muniz, 2005. Disponível em: http://www. bioteriocentral.ufc.br/arquivos/apostilha_manipulacao. pdf. Acesso em: 22 mar. 2011.

RAMÍREZ, A.; SALDANHA, P.H. Análise crítica de grupos controle no teste de micronúcleo na mucosa bucal. Genetics and Molecular Biology, Ribeirão Preto, v.21, supl.3, p. 140, 1998.

RIBEIRO, R.L. Teste do micronúcleo em medula óssea de roedores in vivo. In: RIBEIRO, R.L.; SALVADORI, D.M.F.; MARQUES, E.K. (Org.). Mutagênese ambiental. $1^{\mathrm{a}} \mathrm{ed}$. Canoas: Editora ULBRA, 2003. cap. 7, p.173-200.

SEWRAM, V.; DE STEFANI, E.; BRENNAN, P.; BOFFETTA, $P$. Maté Consumption and the risk of squamous cell esophageal cancer in Uruguay. Cancer Epidemiol Biom Prev.v.12, p. 508-513, 2003.

VALDUGA, E. et al. Caracterização química da folha de llex paraguariensis St. Hil. (erva-mate) e de outras espécies utilizadas na adulteração do mate. Boletim Centro de Pesquisa de Processamento de Alimentos, Curitiba, v.15, n.1, p.25-36, 1997.

WNUK, M. et al. Evaluation of the cyto- and genotoxic activity of yerba mate (Ilex paraguariensis) in human lymphocytes in vitro. Mutation Research, Amsterdan, v.679, n.1-2, p.18-23, 2009.

ZUIN, V.G. et al. Stir bar sorptive extraction and highperformance liquid chromatography-fluorescence detection for the determination of polycyclic aromatic hydrocarbons in Mate teas. Journal of Chromatography, Amsterdan, v.1091, p.2-10, 2005. 